\title{
Endoscopic ultrasound-guided biliary drainage of malignant stenosis, not treatable with endoscopic retrograde cholangio- pancreatography: a single-center, prospective observational study
}

(๑) $\odot$

\begin{abstract}
Authors
Ilaria Tarantino, Marco Peralta, Dario Ligresti, Michele Amata, Luca Barresi, Fabio Cipolletta, Granata Antonio, Mario Traina ${ }^{1}$

Institution

Endoscopy Service, Department of Diagnostic and

Therapeutic Services, IRCCS - ISMETT, Palermo, Italy

submitted 27.3.2019

accepted after revision 6.2 .2020

Bibliography

Endoscopy International Open 2021; 09: E110-E115

DOI 10.1055/a-1313-6850

ISSN 2364-3722

(C) 2021. The Author(s).

This is an open access article published by Thieme under the terms of the Creative Commons Attribution-NonDerivative-NonCommercial License, permitting copying and reproduction so long as the original work is given appropriate credit. Contents may not be used for commecial purposes, or adapted, remixed, transformed or built upon. (https://creativecommons.org/licenses/by-nc-nd/4.0/)

Georg Thieme Verlag KG, Rüdigerstraße 14,

70469 Stuttgart, Germany

Corresponding author

Ilaria Tarantino, MD, Endoscopy Service, IRCCS - ISMETT,

Via Tricomi, 5, 90127 Palermo, Italy

Fax: +39-091-2192400 (specify Endoscopy Service)

itarantino@ismett.edu

\section{ABSTRACT}

Background and study aims The therapeutic role of endoscopic ultrasound (EUS) evolved in recent decade,s opening a new chapter in the field of endoscopic biliary

technique for neoplastic jaundice not amenable to endoscopic retrograde cholangiopancreatography (ERCP). The primary study aims were to assess the clinical efficacy of EUS-BD using an electrocautery-enhanced lumen apposing metal stent (ECE-LAMS) in patients with malignant biliary obstruction with failed)unfeasible ERCP and the adverse event $(A E)$ rate. The secondary aims were to evaluate the technical success and incidence of jaundice recurrence.

Patients and methods Data from All patients referred to our tertiary-care Institute with obstructive jaundice due to unresectable malignant distal biliary stricture and unfeasible|failed ERCP, were prospectively recorded from January 2015 to February 2018. The procedures were performed by a single-step ECE-LAMS (AXIOS-EC, Boston Scientific) placement, from the upper gut lumen to the biliary tree, for definitive biliary decompression.

Results Twenty-one patients were consecutively enrolled. Mean pre-procedure common bile duct diameter was $16 \mathrm{~mm}$ and the bilirubin level was $13.9 \mathrm{mg} / \mathrm{dL}$ (range 3.829.5). LAMS was positioned from the duodenal bulb $(n=$ $19)$ to gastric antrum $(n=2)$. We registered a $100 \%$ of technical and clinical success. No AEs occurred. We observed a single case of delayed AE consisting of a buried LAMS, which was successfully resolved endoscopically.

Conclusions Despite the limits of being non-comparative, our study shows outcomes in a homogeneous population in terms of indications and technique. EUS-BD with dedicated ECE-LAMS is associated with extremely good clinical efficacy and safety and can be considered as an alternative in cases of failed/unfeasible ERCP.
\end{abstract} drainage (BD). EUS-BD has emerged as a new mini-invasive

\section{Introduction}

The therapeutic role of endoscopic ultrasound (EUS) has evolved remarkably in recent years. An accurate EUS visualization of the intrahepatic and extrahepatic biliary ducts, and the ability to easily access these anatomic structures, opened a new chapter in the field of endoscopic biliary drainage. Actually, EUS-guided biliary drainage (EUS-BD) has emerged as a new min- invasive solution for patients with neoplastic jaundice not amenable to endoscopic retrograde cholangiopancreatography (ERCP). Although there are no set guidelines on EUS-BD, a literature review conducted by experts suggests that, when 

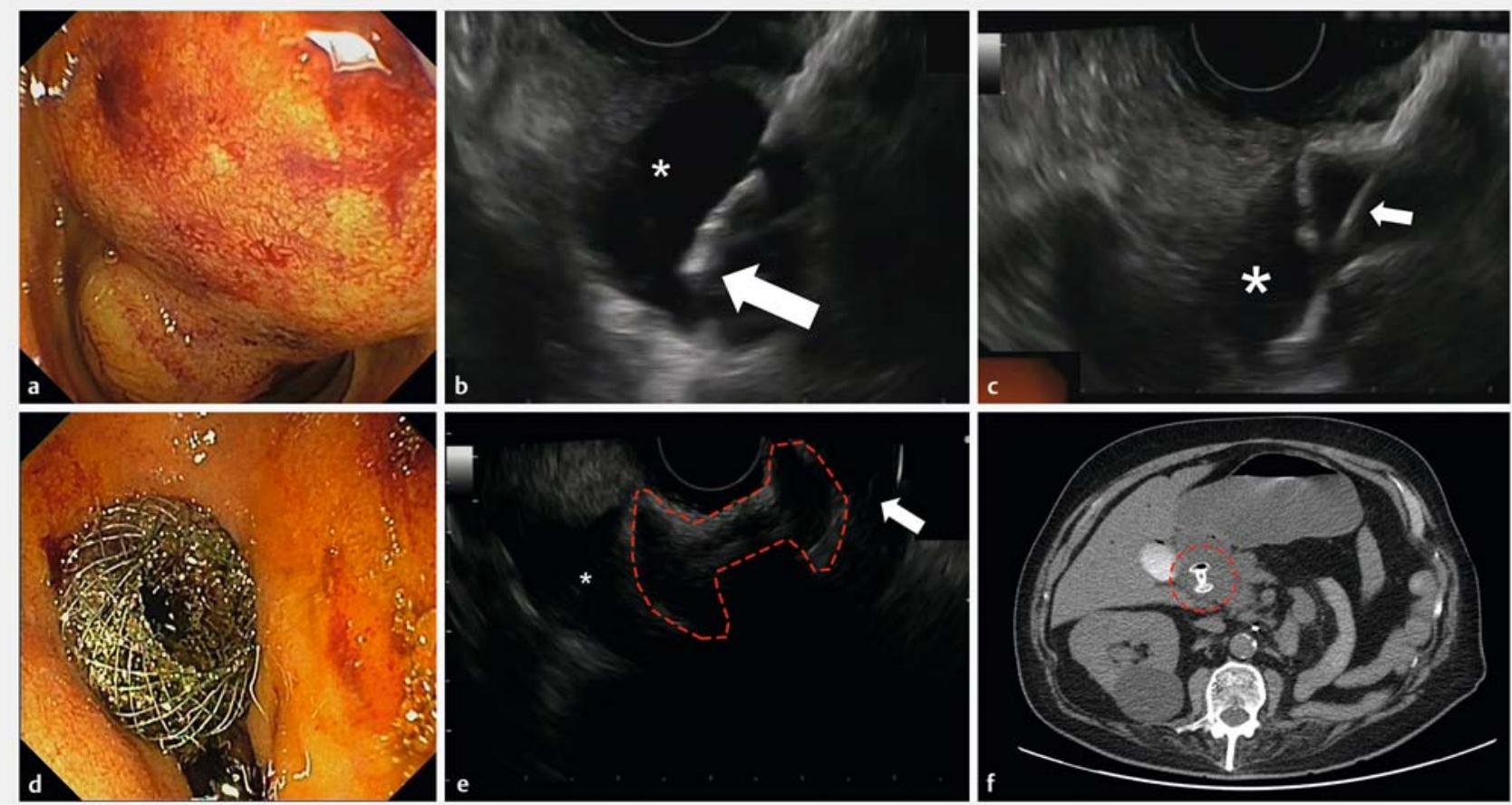

- Fig. 1 Biliary drainage in advanced pancreatic adenocarcinoma: EUS-guided choledocoduodenostomy by LAMS placement. a Inaccessible major papilla due to neoplastic infiltration. $\mathbf{b}$ Distal cautery tip of LAMS catheter inside the CBD (asterisk). $\mathbf{c}$ LAMS catheter (white arrow) and distal flange fully deployed inside the biliary system (asterisk). $\mathbf{d}$ Endoscopic view of proximal flange of the LAMS, perfectly positioned in the duodenal bulb. e EUS evaluation of LAMS profile (dashed red line) with the distal flange in the CBD (asterisk) and proximal one in the duodenum (white arrow). f Computed tomography confirmed the correct position of the LAMS (dashed red circle) 72 hours later.

main bile duct cannulation is not possible with ERCP, EUS-BD performed by an experienced endoscopist should be strongly considered before a radiological or even a surgical intervention [1]. The literature has highlighted that chances of ERCP failure are between $5 \%$ and $10 \%$, even in high-volume hospitals, particularly in cases of neoplastic lesions of the pancreatic head or distal cholangiocarcinoma infiltrating the duodenum and the papilla. Moreover, the most frequent causes leading to ERCP failure are altered anatomy from previous surgery, and duodenal or papillary stenosis secondary to tumor infiltration. Until a few years ago, when failing to cannulate the biliary ducts or to reach the papilla with the ERCP, percutaneous transhepatic biliary drainage (PTBD) or bile duct bypass surgery were the only available options and were associated with high rates of morbidity and mortality [2-4].

The newly available dedicated devices and prostheses for transmural EUS-BD have led to a remarkable change in the clinical management of patients suffering from obstructive jaundice secondary to distal hepatobiliary neoplasm and not treatable with ERCP. In fact, unlike with the rendezvous technique, direct transmural EUS-BD is a well-described technique that requires a single procedure and the same instrument for biliary system decompression when ERCP fails. The true innovation was the introduction of the so-called lumen-apposing metal stent (LAMS). LAMS is a new type of fully-covered self-expanding metal stent (FC-SEMS) with a special design that makes it ideal for creating anastomoses between two hollow organs.
This yo-yo-shaped stent ( $\bullet$ Fig. $\mathbf{1}$ ) has a tubular middle section that supports the fistula tract between the two structures, and flanged ends (larger than the middle section) for correct apposition of the two cavities, preventing migration. The stent is indicated in cases of ERCP failure for drainage of neoplastic cholestatic jaundice using a trans-duodenal EUS-guided approach, creating a definitive choledocoduodenostomy (EUS-CD) as an alternative to EUS-guided hepato-gastrostomy that requires the use of biliary FC-SEMS. Another great advantage was introduction of a new electrocautery-enhanced (ECE) technology, which can be added to the catheter tip, allowing a single-step and exchange-free procedure with no need for further devices (such as a cystotome or papillotome, and dilator) to access the bile duct. In the ECE system, the LAMS is fitted on a cystotome, allowing drainage to be performed with only one device, resulting in a much easier and faster procedure [5-9].

\section{Study goals}

This was a retrospective study of prospectively collected cases conducted in patients with jaundice due to advanced malignant distal biliary obstruction, treated with EUS-BD with ECE-LAMS, following failed (or unfeasible) ERCP. The primary goal was assessment of the clinical efficacy of EUS-BD with a LAMS in the event of failed or unfeasible ERCP. Clinical efficacy was assessed with regard to resolution of jaundice (normalization or minimum $50 \%$ reduction of initial bilirubin levels). 
Secondary goals were:

- Technical success rate of the procedure: correct deployment of the stent with the distal flange into the common bile duct (CBD) and the proximal flange into the lumen of the stomach or the duodenal bulb.

- Estimated rate of adverse events (AEs) related to the procedure: bleeding, perforation, stent spontaneous migrations, or other events requiring any further treatment.

- Recurrence of jaundice within 3 months after treatment.

\section{Patients and methods}

All patients with obstructive jaundice due to unresectable malignant distal biliary stricture and unfeasible or failed ERCP were consecutively included in the study from January 2015 to February 2018. The study was approved by the local Ethics Committee of IRCCS-ISMETT. All patients signed an informed consent for the study. All ERCP procedures were performed under general anesthesia using an Olympus TJF-Q180V duodenoscope (Olympus, Tokyo, Japan) and inflating carbon dioxide. All patients following failed or impractical ERCP were treated during the same session with EUS-BD. The EUS was performed with a GF-UCT180 linear echoendoscope (Olympus, Tokyo, Japan), and drainage done with the AXIOS-EC system (Boston Scientific Corporation, Natick, Massachusetts, United States). This type of stent is produced in different sizes and lengths, but 6 $\mathrm{mm}$ and $8-\mathrm{mm}$ diameters and a saddle length of $8 \mathrm{~mm}$ have been preferably used for biliary access [6]. In our case series, we opted for a larger stent, and in all cases, we used the intrachannel technique to release the proximal flange of the LAMS [7]. The final diameter of the LAMS was selected by the operator. In most procedures, we used a free-hand, single-step technique, with no guidewire. However, in patients with a smallercaliber CBD $(<14 \mathrm{~mm})$, following direct EUS-guided access to the bile duct with the ECE-LAMS delivery system, we inserted a guidewire through the LAMS catheter to preserve access to the biliary tree in order to manage eventual intra-procedural necessities [8].

\section{Results}

Twenty-one patients were consecutively enrolled from January 2015 to February 2018. Of them 42.9\% $(n=9)$ were male, $66.6 \%(n=14)$ had a locally advanced tumor of the pancreatic head, $14.2 \%(n=3)$ had evidence of infiltration in the papillary region, $14.2 \% \mathrm{n}=(3)$ suffered from cholangiocarcinoma of the distal portion of the CBD, and $4.7 \%(n=1)$ had neoplastic infiltration of the duodenum of undetermined origin. In $95.2 \%$ of patients $(n=20)$, the stenosis was located in the distal CBD, and in only $4.7 \%(n=1)$ the stenosis extended proximally to the middle tract of the CBD. ERCP was unfeasible in $57.2 \%(n=$ 12) of patients because of non-visualization of the ampulla of Vater due to neoplastic infiltration of the duodenal wall; in $9.5 \%(n=2)$ there was neoplastic involvement of the stomach that prevented advancement of the scope into the duodenum. In $23.8 \%(n=5)$ ERCP failed due to a tight stenosis of the CBD that could not be passed with a guidewire. In $9.5 \%$ of patients $(n=2)$ there were other causes: one patient showed evidence of a neoplastic stenosis of the upper duodenal knee, resulting in a gastric outlet obstruction (GOO), with upstream liquid and food stagnation; in this case, the ingested materials were suctioned from the stomach and a EUS-guided gastrojejunostomy (EUSG) was created by positioning a first LAMS stent. Following EUS evaluation of cystic-duct patency, a second LAMS was positioned in the gallbladder (EUS-GBD) to achieve retrograde biliary drainage because of neoplastic infiltration of the middledistal third of the CBD. For the second patient, a plastic biliary stent was positioned via standard ERCP. However, due to subsequent worsening of the jaundice, a second ERCP was performed, which showed an ulcer in the papillary region, so an uncovered self-expandable metal stent was positioned. Due to further progression of the neoplasia, another ERCP was planned, which revealed worsening of the papillary neoplastic ulcer, such that the papilla could no longer be accessed.

In $85.7 \%$ of cases, patients were ERCP failures at our institute, attributable to the above-mentioned reasons, while for the remaining $14.3 \%$, the patients were referred to us from other hospitals following a failed procedure. The mean pre-procedure bilirubin level was $13.9 \mathrm{mg} / \mathrm{dL}$ (range 3.8 to 29.5 , DS \pm 6.1). Mean pre-procedure CBD diameter was $16 \mathrm{~mm}$ (range 12 to $20 \mathrm{~mm}$, DS \pm 2.4 ). The LAMS was positioned from the duodenal bulb in $90.48 \%(n=19)$ of cases, and in $9.52 \%(n=2)$, from the gastric antrum ( $\triangleright$ Table 1$)$.

We registered a $100 \%$ technical success rate. The average duration of the procedure was $20 \pm 18$ minutes.

No AEs occurred in the peri-procedure period (within 24 hours). The mean hospital stay was 5 days (range 1 to 30 days). Median follow-up was 188 days (range 8 to 554 days) and the survival time was 161 days (range 8 to 419 days).

All patients had normalization or significant reduction of bilirubin levels. After 2 weeks, the mean bilirubin level was $2.3 \mathrm{mg} / \mathrm{dL}$ (range 0.3 to $9, \mathrm{DS} \pm 2$ ). The jaundice recurrence rate was $14.28 \%$ (3/21 patients): two patients after 35 days and 90 days had food impactions in the Axios stent and one patient developed malignant obstruction after 365 days, all managed endoscopically. There was only one delayed procedurerelated $A E$, which consisted of a buried LAMS 35 days after the EUS-GBD. This complication was resolved endoscopically by positioning a new LAMS with the "LAMS-in-LAMS" technique $(\triangleright$ Table 2) [9].

\section{Discussion}

In patients suffering from resectable pancreatic head cancer and distal cholangiocarcinoma, surgery remains the standard of care, with no indication for biliary drainage, except in cases of cholangitis or irrepressible itching [10]. Conversely, in patients diagnosed with unresectable malignant distal biliary obstruction (approximately $60 \%$ at the time of clinical presentation), the indication is for long-term treatment of jaundice [11].

In these unresectable patients, in the event of ERCP failure (5\% to $10 \%$ ) [12], EUS-BD performed in high-volume centers is supported by several studies published from 2001 to date [13, 14]. The first case report of EUS biliary decompression not 
Table 1 Characteristics of patients and procedures.

\begin{tabular}{|l|l|}
\hline Patients, n. (\%) & 21 \\
\hline Male, n. (\%) & $9(42.9)$ \\
\hline Tumor localization: & $14(66.6)$ \\
\hline - Pancreatic head, n. (\%) & $3(14.2)$ \\
\hline - Invasion of the papillary region, n. (\%) & $3(14.2)$ \\
\hline - Distal cholangiocarcinoma, n. (\%) & $1(4.7)$ \\
\hline - Duodenum infiltration of unknown diagnosis, n. \\
\hline (\%)
\end{tabular}

ERCP, endoscopic retrograde cholangiopancreatography; LAMS, lumen-apposing metal stent.

amenable to ERCP in advanced pancreatic cancer was described by Giovannini et al in 2001 using a 5-Fr needle knife for CBC puncture with subsequent placement of a plastic stent over a biliary guidewire with multiple technical steps [15]. Following technical evolution and technology innovation in the field of endoscopy, Itoi and Binmoeller in 2014 described a successful case report using a newly biflanged LAMS, recently introduced and dedicated for EUS-BD with a transduodenal placement [16].

Kunda et al recently described a series of 57 patients with unresectable distal bile duct obstruction treated with LAMS placement following ERCP failure. They reported good outcomes in terms of both technical and clinical success (respectively of $98.2 \%$ and $94.7 \%$ ). In this study, five patients required a re-intervention for LAMS migration and the AEs rate was $7 \%$ (two duodenal perforations, one bleeding, and one cholangitis) [17].

Another study by Anderloni et al showed encouraging results in terms of LAMS technical success (43/46 patients) with a clinical success rate of $97.7 \%$. However, a not-insignificant AE rate (11.6\%) was reported, with one fatal bleed after 17 days, three episodes of stent occlusion by food impaction, and one spontaneous migration [18].

A prospective multicenter study by Tsuchiya et al evaluated the long-term outcomes of EUS-CD using ECE-LAMS [19]. Nine-
Table 2 Results and follow-up.

\begin{tabular}{|c|c|}
\hline Technical success, n. (\%) & $21(100)$ \\
\hline Clinical success, n. (\%) & $21(100)$ \\
\hline \multicolumn{2}{|l|}{ LAMS size (diameter $\times$ length) } \\
\hline . $6 \mathrm{~mm} \times 8 \mathrm{~mm}$, n. $(\%)$ & $1(4.76)$ \\
\hline . $8 \mathrm{~mm} \times 8 \mathrm{~mm}$, n. $(\%)$ & $16(76.1)$ \\
\hline - $10 \mathrm{~mm} \times 10 \mathrm{~mm}, \mathrm{n} .(\%)$ & $3(14.28)$ \\
\hline - $15 \mathrm{~mm} \times 10 \mathrm{~mm}, \mathrm{n} .(\%)$ & $1(4.76)$ \\
\hline Pretreatment bilirubin level, mean & $13.9 \mathrm{mg} / \mathrm{dl}$ \\
\hline Bilirubin level after 2 weeks, mean & $2.3 \mathrm{mg} / \mathrm{dl}$ \\
\hline Pretreatment CBD size: mean (range), mm & $16(12-20)$ \\
\hline Adverse events, n. (\%) & $1(4.76)$ \\
\hline Reinterventions, n. (\%) & $1(4.76)$ \\
\hline Jaundice recurrence, n. (\%) & $3(17)$ \\
\hline Follow-up: mean (range), days & $188(8-554)$ \\
\hline Survival time: mean (range), days & $161(8-419)$ \\
\hline
\end{tabular}

teen patients with unresectable biliary malignances unamenable to ERCP were treated in five Asian tertiary referral centers with the resolution of jaundice in $95 \%$ of cases $(18 / 19)$. The early procedure-related AEs rate was $15.8 \%$ (cholangitis and fever were observed just in three cases) and stent migration was not reported.

Another retrospective multicenter study from the French group showed $89 \%$ and $100 \%$ rates of technical and clinical success, respectively, in a large population of 52 patients. Of the AEs, $4 \%$ were early, with an increased rate - $14 \%$ - for delayed AEs [20]. Similarly, El Chafic et al retrospectively reviewed the outcomes and clinical success in 67 patients from six different US centers treated with EUS-CD using ECE-LAMS. The overall outcomes were extremely high (technical and clinical efficacy $96 \%$ and $100 \%$, respectively) with an average rate of AEs ( $8 \%$ early and $18 \%$ delayed AEs) [21].

In addition, the study by Khashab et al showed that EUS-BD with ECE-LAMS is correlated with comparable technical and clinical success but lower risk of AEs, shorter hospital stays, and better quality of life compared with PTBD [22].

Our results show that, following ERCP failure, EUS-BD with a single-step LAMS placement is associated with considerably high rates of clinical success in terms of resolution of the biliary obstruction and jaundice. Furthermore, on the basis of the reported absence of severe AEs, it can be considered a safe procedure when performed by experienced professionals. Our study population was approximately $3 \%$ of all patients who underwent ERCP to treat malignant distal biliary stenosis at our institute during the study period. We encountered only one mild complication in our series (which was successfully resolved endoscopically), in line with the AE rates reported in the literature. When evaluating the benefits, it should be borne in mind 
> Table 3 Review of literature about EUS-BD.

\begin{tabular}{|c|c|c|c|c|c|}
\hline Author & Patients & Technical success & Clinical success & Incidence of AEs & Centers and study types \\
\hline Kunda et al. & 57 & $98.2 \%$ & $94.7 \%$ & $7 \%$ & $\begin{array}{l}7 \text { tertiary care centers, retro- } \\
\text { spective }\end{array}$ \\
\hline Anderloni et al. & 46 & $93.4 \%$ & $97.7 \%$ & $11.6 \%$ & $\begin{array}{l}\text { Single tertiary care center, ret- } \\
\text { rospective }\end{array}$ \\
\hline Tsuchiya et al. & 19 & $95 \%$ & $95 \%$ & $15.8 \%$ & $\begin{array}{l}5 \text { Asian tertiary care centers; } \\
\text { prospective }\end{array}$ \\
\hline Jacques et al. & 52 & $89 \%$ & $100 \%$ & Early:4\% Late:14\% & $\begin{array}{l}\text { French multicenter study; retro- } \\
\text { spective }\end{array}$ \\
\hline El Chafic et al. & 67 & $96 \%$ & $100 \%$ & Early:8\% Late:18\% & $\begin{array}{l}\text { US multicenter study; retro- } \\
\text { spective }\end{array}$ \\
\hline Paik WH et al. & 64 EUS vs 61 ERCP & $93.8 \%$ vs $90.2 \%$ & $90.0 \%$ vs $94.5 \%$ & $6.3 \%$ vs $19.7 \%$ & $\begin{array}{l}\text { Multicenter randomized con- } \\
\text { trolled trial }\end{array}$ \\
\hline Bang JY et al. & 33 EUS vs 34 ERCP & $90,9 \%$ vs $94,1 \%$ & $97 \%$ vs $91.2 \%$ & $21.2 \%$ vs $14.7 \%$ & $\begin{array}{l}\text { Single-center, single-blind, ran- } \\
\text { domized comparative trial }\end{array}$ \\
\hline Khashab MA et al. & 22 EUS vs 51 PTBD & $86,4 \%$ vs $100 \%$ & $\begin{array}{l}86.4 \% \text { vs } \\
92.2 \%\end{array}$ & $15.7 \%$ vs $80.4 \%$ & $\begin{array}{l}\text { Single tertiary care center; com- } \\
\text { parative }\end{array}$ \\
\hline
\end{tabular}

EUS, endoscopic ultrasound; ERCP, endoscopic retrograde cholangiopancreatography; PTBD, percutaneous transhepatic biliary drainage.

that in the event of ERCP failure, the EUS-guided procedure can be performed during the same session and with the same sedation. On one hand, this precludes the anesthesia-related risks of a second procedure and, on the other hand, it reduces the patient's overall hospital stay.

Recently, EUS-BD was compared with ERCP as a primary therapy in patients with unresectable malignant distal biliary obstruction. A recently published multicenter, randomized controlled trial (RCT) compared two arms where EUS-guided vs. ERCP drainage were used as primary palliation in $125 \mathrm{pa}-$ tients with distal malignant biliary obstruction. Results showed comparable technical (EUS $93 \%$ vs. ERCP $90 \%$ ) and clinical (EUS $90 \%$ vs. ERCP $94 \%$ ) success rates. However, the EUS-guided approach showed a significantly lower rates of AEs (EUS $6.3 \%$ vs. ERCP $19.7 \%)(P=0.03)$ and reintervention (15.6\% vs. $42.6 \%)(P$ $=0.001)$. The risk of pancreatitis in the EUS arm was $0 \%$ vs. $15 \%$ in ERCP patients [23]. Similarly, the study of Bang et all published in 2018 showed no significant differences in terms of $A E s$, in treatment success or in median survival time between the EUS-BD and ERCP approaches in this advanced clinical setting (67 randomize patients) ( Table 3 ) [24]. In addition, 396 patients were identified in a recent meta-analysis from a Canadian multicenter group comparing ERCP and EUS, and the authors have showed no difference between the two approaches in terms of overall clinical success, procedure time, and risk of stent occlusion. Even if there was no significant difference in global AE, EUS-BD has been confirmed to present a reduced risk of post-procedural acute pancreatitis [25]. If requisite technical expertise is available, the authors demonstrated the reasonableness of EUS procedures in locally advanced or metastatic cancer, not only in unresectable patients but also in potential candidates for surgery. In fact, EUS-guided transduodenal LAMS placement may not negatively impact surgical technique, as the site of transmural puncture is part of the operative specimen. In this setting of surgical candidates requiring a biliary drainage, another option, when technically feasible, is also to perform EUS-GBD as a bridge-to-surgery approach that preserves the integrity of the $\mathrm{CBD}$, allowing the surgeon to proceed with a standard Whipple resection with a safe bilioenteric anastomosis [26].

Finally, despite the limits of being non-comparative, our study has the advantage of presenting outcomes in a homogeneous patient population in terms of indication and technique.

\section{Conclusions}

Our results confirm that the technique of ECE-LAMS is associated with extremely good rates of clinical efficacy and safety. In light of both the existing literature and of our results, in highvolume centers, EUS-BD can be considered as an alternative treatment option for failed or unfeasible ERCP. To affirm that EUS-BD represents a first-choice alternative to ERCP, the recently published results need to be confirmed by further RCTs.

\section{Competing interests}

The authors declare that they have no conflict of interest.

\section{References}

[1] Lawa R, Baron TH. Endoscopic ultrasound - guided biliary interventions an update on recent developments. Curr Opin Gastroenterol 2016; 32: 232-237 
[2] Boulay BR, Parepally M. Managing malignant biliary obstruction in pancreas cancer: choosing the appropriate strategy. World J Gastroenterol 2014; 20: 9345-9353

[3] Udd M, Kylänpää L, Halttunen J. Management of difficult bile duct cannulation in ERCP. World J Gastrointest Endosc 2010; 2: 97-103

[4] Peng C, Nietert P], Cotton PB et al. Predicting native papilla biliary cannulation success using a multinational endoscopic retrograde cholangiopancreatography (ERCP) quality network. BMC Gastroenterol 2013; 13: 147

[5] Leng J], Zhang N, Dong JH. Percutaneous transhepatic and endoscopic biliary drainage for malignant biliary tract obstruction: a metaanalysis. World J Surg Oncol 2014; 12: 272

[6] Weilert F, Binmoeller KF. Endoscopic ultrasound-assisted pancreaticobiliary access. Gastrointest Endosc Clin N Am 2015; 25: 805-826

[7] Anderloni A, Attili F, Carrara S et al. Intra-channel stent release technique for fluoroless endoscopic ultrasound-guided lumen-apposing metal stent placement: changing the paradigm. Endosc Int Open 2017; 5: E25-E29

[8] Ligresti D, Amata M, Granata A et al. Salvage procedure following lumen-apposing metal stent maldeployment during endoscopic ultrasound-guided biliary drainage. Endoscopy 2018; 50: E190-E191

[9] Ligresti D, Cipolletta F, Amata M et al. Buried lumen-apposing metal stent (LAMS) following endoscopic ultrasound-guided gallbladder drainage: the LAMS-in-LAMS rescue treatment. Endoscopy 2018; 50 : 822-823

[10] Dumonceau JM, Tringali A, Papanikolaou IS et al. Endoscopic biliary stenting: indications, choice of stents, and results: European Society of Gastrointestinal Endoscopy (ESGE) Clinical Guideline - Updated October 2017. Endoscopy 2018; 50: 910-930

[11] Bapaye A, Dubale N, Aher A. Comparison of endosonography-guided vs. percutaneous biliary stenting when papilla is inaccessible for ERCP. United European Gastroenterol J 2013; 1: 285-293

[12] Holt BA, Hawes R, Hasan M et al. Biliary drainage: role of EUS guidance. Gastrointest Endosc 2016; 83: 160-165

[13] Fabbri C, Fugazza A, Binda C et al. Beyond palliation: using EUS-guided choledochoduodenostomy with a lumen-apposing metal stent as a bridge to surgery. A case series. J Gastrointestin Liver Dis 2019; 28: $125-128$

[14] Jacques J, Privat J, Pinard F et al. Endoscopic ultrasound-guided choledochoduodenostomy with electrocautery-enhanced lumen-apposing stents: a retrospective analysis. Endoscopy 2019; 51: 540-547

[15] Giovannini M, Moutardier V, Pesenti C et al. Endoscopic ultrasoundguided bilioduodenal anastomosis: a new technique for biliary drainage. Endoscopy 2001; 33: 898-900
[16] Itoi T, Binmoeller KF. EUS-guided choledochoduodenostomy by using a biflanged lumen-apposing metal stent. Gastrointest Endosc 2014; 79: 715

[17] Kunda R, Pérez-Miranda M, Will U et al. EUS-guided choledochoduodenostomy for malignant distal biliary obstruction using a lumen-apposing fully covered metal stent after failed ERCP. Surg Endosc 2016; 30: 5002-5008

[18] Anderloni A, Fugazza A, Troncone E et al. Single-stage EUS-guided choledochoduodenostomy using a lumen-apposing metal stent for malignant distal biliary obstruction. Gastrointest Endosc 2019; 89: 69-76

[19] Tsuchiya T, Teoh AYB, Itoi T et al. Long-term outcomes of EUS-guided choledochoduodenostomy using a lumen-apposing metal stent for malignant distal biliary obstruction: a prospective multicenter study. Gastrointest Endosc 2018; 87: 1138-1146

[20] Jacques ], Privat J, Pinard F et al. Endoscopic ultrasound-guided choledochoduodenostomy with electrocautery-enhanced lumen-apposing stents: a retrospective analysis. Endoscopy 2019; 51: 540-547

[21] El Chafic AH, Shah JN, Hamerski C et al. EUS-Guided choledochoduodenostomy for distal malignant biliary obstruction using electrocautery-enhanced lumen-apposing metal stents: first US, multicenter experience. Dig Dis Sci 2019; 64: 3321-3327

[22] Khashab MA, Valeshabad AK, Afghani E et al. A comparative evaluation of EUS-guided biliary drainage and percutaneous drainage in patients with distal malignant biliary obstruction and failed ERCP. Dig Dis Sci 2015; 60: 557-565

[23] Paik WH, Lee TH, Park DH et al. EUS-guided biliary drainage versus ERCP for the primary palliation of malignant biliary obstruction: a multicenter randomized clinical trial. Am J Gastroenterol 2018; 113 : 987-997

[24] Bang JY, Navaneethan U, Hasan M et al. Stent placement by EUS or ERCP for primary biliary decompression in pancreatic cancer: a randomized trial (with videos). Gastrointest Endosc 2018; 88: 9-17

[25] Bishay K, Boyne D, Yaghoobi M et al. Endoscopic ultrasound-guided transmural approach versus ERCP-guided transpapillary approach for primary decompression of malignant biliary obstruction: a meta-analysis. Endoscopy 2019; 51: 950-960

[26] Ligresti D, Tarantino I, Amata M et al. Bridge-to-surgery gallbladder drainage with a lumen-apposing metal stent in malignant distal biliary obstruction: a choice tailored for the surgeon. Endoscopy 2019; 51: 94-95 